\title{
Preparation of Adamantyl
}

\section{and t-butyl Oximes Derivatives of 1,3-} and 1,4-Dihydroxynaphthalene Diketone Tautomers

\author{
Ivan V. Peterson*a, Nadezhda M. Svirskaya ${ }^{a}$, \\ Alexander A. Kondrasenko a and Anatoliy I. Rubaylo ${ }^{\mathbf{a}, \mathbf{b}}$ \\ anstitute of Chemistry and Chemical Technology SB RAS \\ FRC "Krasnoyarsk Science Center SB RAS" \\ 50/24 Akademgorodok, Krasnoyarsk, 660036, Russia \\ ${ }^{b}$ Siberian Federal University \\ 79 Svobodny, Krasnoyarsk, 660041, Russia
}

Received 09.03.2017, received in revised form 21.06.2017, accepted 30.07.2017

Adamantyl and tert-butyl derivatives of 1,4-dihydroxynaphthalene diketone tautomer react with hydroxylamine in the pyridine and methanol medium with formation of corresponding monooximes. In the case of 1,3-dihydroxynaphthalene diketone tautomer only adamantylated oxime was synthesized.

Keywords: adamantane, oximation, diketone forms of dihydroxynaphthalenes.

(C) Siberian Federal University. All rights reserved

* Corresponding author E-mail address: Ivan.Peterson.Krsk@gmail.com 


\title{
Получение оксимов адамантильных
}

и трет-бутильных производных

дикетонных таутомеров 1,3- и 1,4-дигидроксинафталинов

\author{
И.В. Петерсон ${ }^{\mathrm{a}}$ Н.М. Свирская ${ }^{\mathrm{a}}$, \\ А.А. Кондрасенко ${ }^{\text {a }, \text { А.И. Рубайло }}{ }^{\text {, }}$ \\ ${ }^{a}$ Институт химии и химической технологии СО РАН \\ ФИЦ «Красноярский научный цуентр СО РАН» \\ Россия, 660036, Красноярск, Академгородок, 50/24 \\ ${ }^{6}$ Сибирский федеральный университет \\ Россия, 660041, Красноярск, пр. Свободный, 79
}

\begin{abstract}
При взаимодействии адамантильных и трет-бутильных производных дикетонного таутомера 1,4-дигидроксинафталина с гидроксиламином в среде пиридина и метанола образуются их соответствующие монооксимы. В случае дикетонного таутомера 1,3-дигидроксинафталина был синтезирован оксим только адамантилированного соединения.
\end{abstract}

Ключевые слова: адамантан, оксимирование, дикетонные формы дигидроксинафталинов.

В настоящее время обозначился значительный интерес к различным деароматизованным соединениям в связи с тем, что была обнаружена важнейшая роль дикетонных таутомеров гидро- и нафтохинонов, а также дигидроксинафталинов в процессах биосинтеза и детоксикации [1].

К данному моменту известно о возможности образования 1,4-дигидроксинафталином кинетически стабильного таутомера - 2,3-дигидронафталин-1,4-диона. Данное соединение является многообещающим исходным материалом в различных органических синтезах, но его свойства и реакционная способность, а также возможности образования различных производных до сих пор мало изучены. В этой связи в последние годы наблюдается значительный интерес исследователей к изучению его свойств и реакций [2-5].

В свою очередь, сведения о кето-енольных превращениях 1,3-дигидроксинафталина и регистрации его таутомера 2,4-дигидронафталина-1,3-диона в литературе отсутствуют (кроме комплекса с $\mathrm{AlBr}_{3}$ ) [6]. В работах [7-9] упоминается лишь о перспективных свойствах 1,3-дигидроксинафталина вследствие специфичного расположения гидроксильных групп.

Среди трет-алкилзамещенных производных дикетоформ 1,3- и 1,4-дигидроксинафталинов известно лишь об образовании посредством фотолиза 2-(трет-бутил)-2,3-дигидронафталин-1,4диона [10]. Другие сведения о получении и изучении свойств подобных трет-алкилзамещенных соединений к настоящему моменту отсутствуют.

Недавно нами было показано, что 1,4-дигидроксинафталин взаимодействует с третичными спиртами (1-адамантанол и трет.бутанол) при комнатной температуре в трифторуксусной кислоте в таутомерной форме, образуя 2-(1-адамантил)-2,3-дигидронафталин1,4-дион (I) и 2-(трет-бутил)-2,3-дигидронафталин-1,4-дион (II) [11, 12]. Дальнейшее их 
взаимодействие с гидроксиламином в среде пиридина и метанола при нагревании приводит к образованию 2-(1-адамантил)-2,3-дигидронафталин-1-он-4-оксима (III) и 2-(трет-бутил)-2,3дигидронафталин-1-он-4-оксима (IV). Общая схема синтеза оксимов III и IV представлена на рис. 1.

Необходимо отметить, что 2-(1-адамантил)-1,4-нафтохинон, который образуется при восстановлении дикетона I $[11,12]$, в аналогичных условиях в реакцию оксимирования не вступает. Но нами было обнаружено, что синтезированные ранее [13] 2-(адамантил)-1,6дигидроксинафталин (V) и 3-(адамантил)-1,7-дигидроксинафталин (VI) со временем окисляются на воздухе в один и тот же продукт - 2-(1-адамантил)-6-гидрокси-1,4-нафтохинон (VII). Соединение VII также было получено окислением окисью хрома $\left(\mathrm{CrO}_{3}\right)$ соединений V и VI. В свою очередь, соединение VII вступает в реакцию оксимирования с образованием 2-(1-адамантил)-6-гидрокси-1,4-нафтохинон-4-оксима (VIII). Общая схема синтеза соединений VII и VIII представлена на рис. 2.

В случае 1,3-дигидроксинафталина ранее было показано, что при его взаимодействии с 1-адамантанолом при нагревании в течение 6 ч в смеси уксусной и фосфорных кислот образуется 4-(1-адамантил)-2,4-дигидронафталин-1,3-дион (IX) [14, 15]. В аналогичных условиях с реакцией оксимирования соединения I был получен 4-(1-адамантил)-2,4-дигидронафталин-3он-1-оксим (X). Общая схема синтеза соединений $\mathbf{I X}$ и $\mathbf{X}$ изображена на рис. 3.

Однако при реакции 1,3-дигидроксинафталина с трет-бутанолом в подобных условиях при увеличении времени нагрева образуется смесь продуктов алкилирования, состоящая из

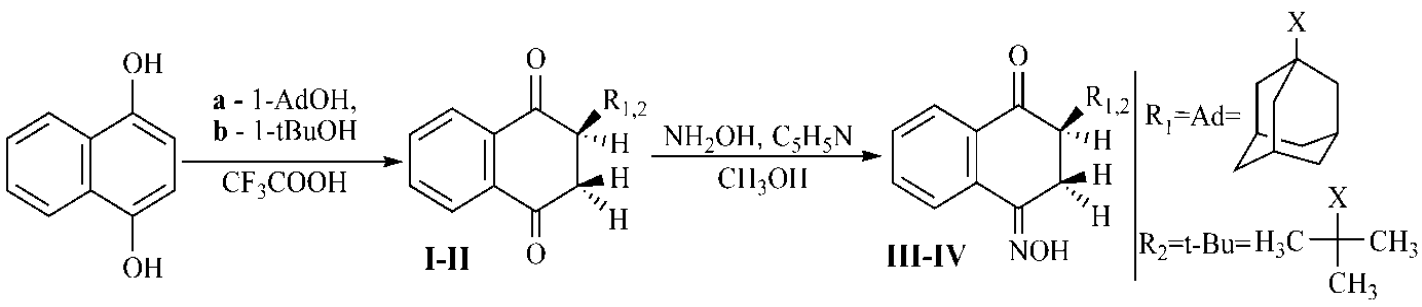

Рис. 1. Схема синтеза оксимов III и IV

Fig. 1. Synthesis of oximes III and IV

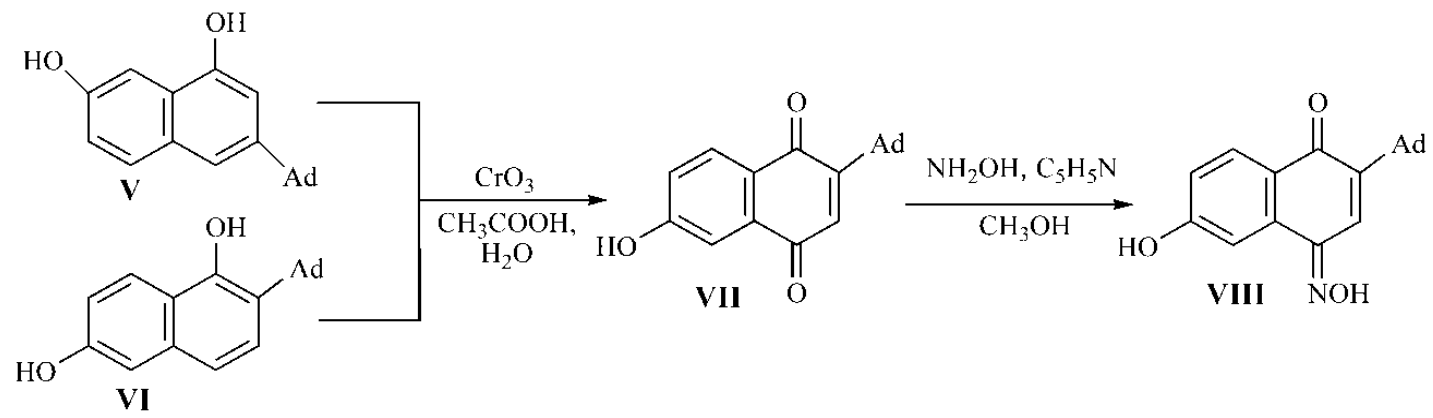

Рис. 2. Схема синтеза соединения VII и его оксима VIII

Fig. 2. Synthesis of compound VII and their oxime IV 


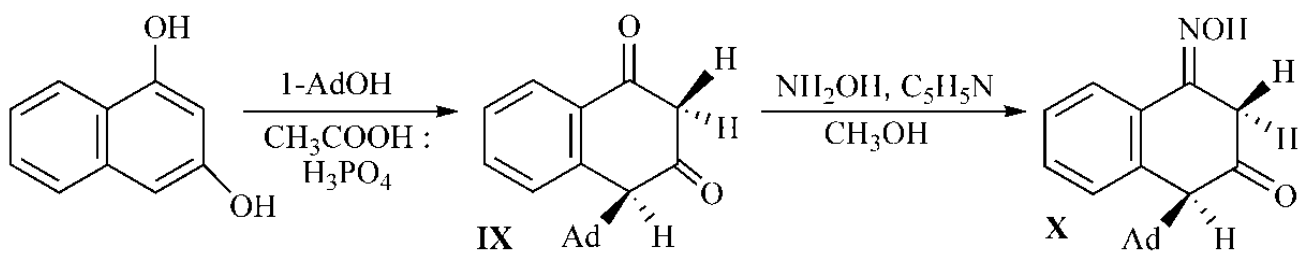

Рис. 3. Схема синтеза соединения IX и его оксима X

Fig. 3. Synthesis of compound IX and their oxime X

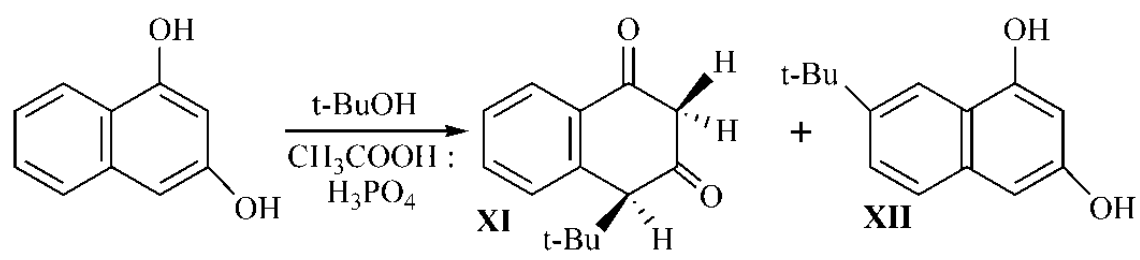

Рис.4. Схема синтеза соединений XI и XII

Fig. 4. Synthesis of compounds XI and XII

таутомерной (кетоной) формы [4-(трет.бутил)-2,4-дигидронафталин-1,3-диона (XI)] и енольной формы дигидроксинафталина [7-(трет.бутил)-1,3-дигидроксинафталина (XI)]. Получение оксима соединения XI из данной реакционной смеси не представляется возможным. Схема синтеза соединений XI и XII дана на рис. 4.

Таким образом, были синтезированы и охарактеризованы адамантильные и третбутильные производные 1,3- и 1,4-дигидроксинафталинов и их оксимы. При этом показано, что в синтезированных дикетоформах в реакцию предпочтительно вступает одна карбонильная группа. Малую реакционную способность второй карбонильной группы можно объяснить стерическими препятствиями, создаваемыми объёмным адамантильным заместителем и третбутильным фрагментом. Стерическими препятствиями также можно объяснить факт того, что реакция оксимирования 2-(1-адамантил)-1,4-нафтохинона не протекает. Возможно, что наличие в соединении VII донорного заместителя (гидроксильной группы) в шестом положении оказывает активирующее действие в реакции оксимирования.

В заключение необходимо отметить, что интерес к получению и изучению свойств азотсодержащих производных адамантилированных нафталиндиолов (включая их дикетонные формы) обусловлен тем, что наибольшее количество веществ с адамантановым каркасом и установленной биологической активностью содержат в своей структуре азотные и ароматические компоненты.

\section{Экспериментальная часть}

Спектры ЯМР зарегистрированы на спектрометре Bruker Avance III 600 ('H - 600.13 МГц, ${ }^{13} \mathrm{C}-150.90$ МГц) Красноярского регионального центра коллективного пользования ФИЦ КНЦ CO РАН. Элементные анализы выполнены на приборе Flash EA 1112TM.

Описание синтеза и строения соединений I-II, V-VI и IX приведено в работах [11-15].

$$
-307-
$$




\section{2-(1-адамантил)-2,3-дигидронафталин-1-он-4-оксим (III)}

0.294 г (0.001 м) 2-(1-адамантил)-2,3-дигидронафталин-1,4-диона нагревали с 0.077 г $\mathrm{NH}_{2} \mathrm{OH} \cdot \mathrm{HCl}$ в смеси 3 мл метанола и 3 мл пиридина на водяной бани в течение часа. После удаления растворителей реакционную смесь промывали разбавленной соляной кислотой и водой. Сушили. Выход 0.19 г (62 \%). Т. пл.: 96-97 ${ }^{\circ}$ C. Найдено, \% C 78.14; H 7.51; N 4.60. $\mathrm{C}_{20} \mathrm{H}_{23} \mathrm{NO}_{2}$. Вычислено, \%: С 72.17, Н 7.49, N 4.56. Спектр ЯМР $\left(\mathrm{CD}_{2} \mathrm{Cl}_{2}\right):{ }^{1} \mathrm{H}, \delta$, м.д 1.53-1.66 (м, 6H, Ad-CH $), 1.56$ (м, 6H, Ad- $\mathrm{CH}_{2}$ ), 1.90 (м, 3H, Ad-CH), 2.42 (дд, J=7.0, J=2.8, 1H, H-3a), 2.65 (дд, J=17.1, J=7.0, 1H, H-3b), 3.78 (дд, J=17.1, J=2.8, 1H, H-2), 7.48 (м, 1Н, H-6), 7.56 (м, 1Н, H-7), 7.84 (уш.с., 1Н, NOH), 7.93 (м, 1Н, H-5), 7.98 (м, 1Н, H-8); ${ }^{13} \mathrm{C}, \delta$, м.д. (ацетон-d ${ }_{6}$ ): 22.9 (C-3), 29.6 (Ad-CH), 36.8 (Ad-C), 37.5 (Ad- $\left.\mathrm{CH}_{2}\right), 41.2\left(\mathrm{Ad}^{-\mathrm{CH}_{2}}\right), 57.3$ (C-2), 124.2 (C-5), 127.1 (C-8), 130.4 (C-6), 134.1 (C-7), 134.7 (C-1a), 137.5 (C-4a), 152.4 (C-4), 199.1 (C-1).

\section{2-(трет-бутил)-2,3-дигидронафталин-1-он-4-оксим (IV)}

0.218 г (0.001 м) 2-(трет-бутил)-2,3-дигидронафталин-диона нагревали с 0.077 г $\mathrm{NH}_{2} \mathrm{OH} \cdot \mathrm{HCl}$ в смеси 3 мл метанола и 3 мл пиридина на водяной бани в течение часа. После удаления растворителей реакционную смесь промывали разбавленной соляной кислотой и водой. Сушили. Темно-серое масло. Выход 0.19 г (5 \%). Спектр ЯМР $\left(\mathrm{CDCl}_{3}\right):{ }^{1} \mathrm{H}, \delta$, м.д.: 1.02 (c, 9H, tBu-CH$)$, 2.65 (дд, J=6.6, J=1.6, 1H, H-2), 2.98 (дд, J=16.9, J=6.6, 1Н, Н-3a), 3.57 (дд, J=16.9, J=4.6, 1H, Н3-b), 7.50 (т, J=7.0, 1H, Н-6), 7.59 (м, 1Н, H-7), 7.98 (д, J=8.1, 1Н, H-5), 8.00 (д, J=7.8, 1Н, Н-8), 8.51 (уш.с, $1 \mathrm{H}, \mathrm{NOH}) ;{ }^{13} \mathrm{C}, \delta$, м.д.: 23.8 (C-3), $28.3\left(\mathrm{tBu}-\mathrm{CH}_{3}\right.$ ), 34.1 (tBu-C), 55.1 (C-2), 123.3 (C-5), 126.9 (C-8), 130.1 (C-6), 133.5 (C-1a), 133.6 (C-7), 135.3 (C-4a), 153.4 (C-4), 199.5 (C-1).

\section{2-(1-адамантил)-6-гидрокси-1,4-нафтохинон (VII)}

К 0.294 г (0.001 м) соединений $\mathbf{V}$ или $\mathbf{V I}$ растворенным в $\mathrm{CH}_{3} \mathrm{COOH}$ добавляли 0.5 г $\mathrm{CrO}_{3}$ в смеси $\mathrm{H}_{2} \mathrm{O}$ и $\mathrm{CH}_{3} \mathrm{COOH}$. Температуру смеси повышали до $35^{\circ} \mathrm{C}$, затем поддерживали температуру при $40{ }^{\circ} \mathrm{C}$. Выход 0.283 г (92 \%). Т. пл.: $210-211^{\circ} \mathrm{C}$ (разл). Найдено, \% C 77.95; Н 6.49; $\mathrm{C}_{20} \mathrm{H}_{20} \mathrm{O}_{3}$. Вычислено, \%: С 77.77, Н 6.49. Спектр ЯМР $\left(\mathrm{CDCl}_{3}\right)$ : ${ }^{1} \mathrm{H}, \delta$, м.д.: 1.80 (м, 6H, $\left.\mathrm{Ad}-\mathrm{CH}_{2}\right), 2.03$ (м, 6H, Ad- $\mathrm{CH}_{2}$ ), 2.10 (м, 3H, Ad-CH), 5.81 (уш.с, 1H, OH), 6.71 (с, 1H, H-3), 7.15 (д, J=8.5, 1H, H-7), 7.44 (с, 1H, H-5), 7.99 (д, J=8.7, 1H, H-8); ${ }^{13} \mathrm{C}, \delta$, м.д.: 28.5 (Ad-CH), 36.7 (Ad- $\mathrm{CH}_{2}$ ), 38.3 (Ad-C), 40.6 (Ad- $\mathrm{CH}_{2}$ ), 111.4 (C-5), 120.7 (C-7), 127.6 (C-1a), 129.9 (C-8), 133.5 (C-4a), 134.0 (C-3), 158.6.1 (C-2), 160.0 (C-6), 183.7 (C-1), 186.0 (C-4).

\section{2-(1-адамантил)-6-гидрокси-1,4-нафтохинон-4-оксим (VIII)}

0.308 г (0.001 м) соединения VII нагревали с 0.077 г $\mathrm{NH}_{2} \mathrm{OH} \cdot \mathrm{HCl}$ в смеси 3 мл метанола и 3 мл пиридина на водяной бани в течение часа. После удаления растворителей реакционную смесь промывали разбавленной соляной кислотой и водой. Сушили. Выход 0.283 г (62 \%). Т. пл.: 167-168 ${ }^{\circ} \mathrm{C}$. Найдено, \% C 74.28; Н 6.56; N 4.33. $\mathrm{C}_{20} \mathrm{H}_{21} \mathrm{NO}_{3}$. Вычислено, \%: С 74.31, Н 6.52, N 4.31. Спектр ЯМР (ацетон-d ${ }_{6}$ ): ${ }^{1} \mathrm{H}, \delta$, м.д.: 1.80 (м, 6H, Ad- $\mathrm{CH}_{2}$ ), 2.06 (м, 3H, Ad-CH), 2.09 (м, 3Н, Ad-CH $)_{2}, 7.03$ (дд, J=8.1, J=2.5 1H, H-7), 7.55 (д, J=2.5, 1H, H-5), 7.79 (с, 1H, H-3), 7.99 (д, J=8.7, 1H, H-8), 9.22 (уш.с, 1H, OH-6), 11.88 (уш., $1 \mathrm{H}, \mathrm{NOH}) ;{ }^{13} \mathrm{C}, \delta$, м.д.: 29.7 (Ad-CH), 37.7 (Ad-CH ( $_{2}, 38.9$ (Ad-C), 41.3 (Ad-CH A $_{2}, 107.6$ (C-5), 118.6 (C-7), 121.4 (C-3), 126.1 (C-1a), 130.0 (C-8), 135.8 (C-4a), 147.1 (C-4), 150.3 (C-2), 161.9 (C-6), 184.1 (C-1).

\section{4-(1-адамантил)-2,4-дигидронафталин-1,3-дион-1-оксим (X)}

0.294 г (0.001 м) 2-(1-адамантил)-2,4-дигидронафталин-1,3-диона нагревали с 0.077 г $\mathrm{NH}_{2} \mathrm{OH} \cdot \mathrm{HCl}$ в смеси 3 мл метанола и 3 мл пиридина на водяной бани в течение часа. После уда- 
ления растворителей реакционную смесь промывали разбавленной соляной кислотой и водой. Сушили. Выход 0.17 г (59 \%). Т. пл.: $115^{\circ} \mathrm{C}$ (разл.). Найдено, \% C 78.20; Н 7.47; N 4.60. $\mathrm{C}_{20} \mathrm{H}_{23} \mathrm{NO}_{2}$. Вычислено, \%: С 72.17, Н 7.49, N 4.56. Спектр ЯМР $\left(\mathrm{CDCl}_{3}\right)$ : ${ }^{1} \mathrm{H}, \delta$, м.д.: 1.47 (м, 6H, Ad- $\mathrm{CH}_{2}$ ), 1.76-1.83 (м, 6H, Ad-CH ${ }_{2}$ ), 1.96 (м, 3H, Ad-CH), 3.22 (с, 1H, H-4), 3.77 (д, J=22.9, 1H, H-2a), 3.92 (д, J=22.6, 1Н, Н-2b), 7.14 (д, J=7.6, 1Н, Н-5), 7.30 (т, J=7.6, 1Н, Н-6), 7.35 (т, J=6.9, 1Н, Н-7), 7.78 (д, J=7.6, 1H, H-8), 9.05 (уш.с, 1H, NOH); ${ }^{13} \mathrm{C}, \delta$, м.д.: 25.2 (C-2), 30.7 (Ad-CH), 36.1 (Ad-CH C $_{2}, 38.0$ (Ad-C), 40.4 (Ad-CH A $_{2}, 57.1$ (C-4), 124.8 (C-8), 127.3 (C-6), 129.0 (C-7), 130.8 (C-5), 131.7 (C-1a), 136.0 (C-4a), 147.1 (C-1), 155.41 (C-3).

Реакционная смесь: 4-(трет.бутил)-2,4-дигидронафталин-1,3-дион (XI) и 7-(трет.бутил)-

\section{1,3-дигидроксинафталин (XII)}

0.160 г (1 ммоль) 1,3-дигидроксинафталина и 0.0074 г (1 ммоль) трет-бутанола нагревали в ампуле при $60{ }^{\circ} \mathrm{C}$ в смеси 0.6 мл $\mathrm{CH}_{3} \mathrm{COOH}$ и 1.5 мл $85 \% \mathrm{H}_{3} \mathrm{PO}_{4}$ в течение 15 ч. После охлаждения реакционную смесь обрабатывали ледяной водой, отфильтровывали осадок и промывали его несколько раз до нейтральной реакции. Сушили. Общий выход: 0.090 г (40 \%, из них XI 0.060 г, XII - 0.022 г).

Спектр ЯМР $\left(\mathrm{CDCl}_{3}\right)$ соединения XI: ${ }^{1} \mathrm{H}, \delta$, м.д.: 0.95 (c, 9H, tBu-CH$\left.{ }_{3}\right), 3.5$ (дд, J=21.3, J=1.4, 1H, H-2a), 3.52 (с, 1Н, Н-4), 3.58 (д, J=21.5, 1Н, H-2b), 7.27 (д, J=7.8, 1Н, Н-5), 7.45 (тд, J=7.8, J=1.1, 1H, Н-6), 7.59 (тд, J=7.6, J=1.4, 1Н, Н-7), 8.07 (дд, J=7.8, J=0.95, 1Н, Н-8).

Спектр ЯМР $\left(\mathrm{CDCl}_{3}\right)$ соединения XII: ${ }^{1} \mathrm{H}, \delta$, м.д.: 1.41 (c, $\left.9 \mathrm{H}, \mathrm{tBu}_{-} \mathrm{CH}_{3}\right), 4.20$ (уш.c, $2 \mathrm{H}, \mathrm{OH}$ ), 6.51 (c, 1H, H-3), 6.73 (с, 1H, H-4), 7.54 (м, 1H, H-6), 7.58 (м, 1Н, H-5), 8.00 (уш.с, $1 \mathrm{H}, \mathrm{H}-8$ ); ${ }^{13} \mathrm{C}, \delta$, м.д.: 31.1 (tBu-C), 31.3 (tBu-CH ), 100.9 (C-2), 102.1 (C-4), 126.1 (C-8), 119.8 (C-1a), 126.0 (C-6), 116.4 (C-5), 133.6 (C-4a), 145.7 (C-7), 152.9 (C-1), 153.0 (C-3).

Исследование выполнено при финансовой поддержке РФФИ в рамках научного проекта № 16-33-00094 мол_а.

\section{Список литературы}

1. Husain S. M., Schatzle M. A., Ludeke S., Muller M.Unprecedented role of hydronaphthoquinone tautomers in biosynthesis. Angew. Chem. Int. Ed. 2014, V. 53, p. 9806-9811.

2. Pearson M. S, Jensky B. J., Greer F. X., Hagstrom J. P., Wells N. M. Substituent effects in the keto-enol tautomerism of fused 1,4-naphthalenediols. J. Org. Chem. 1978. V. 43, p. 4617-4622.

3. Kündig E. P., Garcia A., Lomberget T., Bernardinelli G. Rediscovery, isolation, and asymmetric reduction of 1,2,3,4-tetrahydronaphthalene-1,4-dione and studies of its $\left[\mathrm{Cr}(\mathrm{CO})_{3}\right]$ complex. Angew. Chem. Int. Ed. 2006. V. 45, p. 98-101.

4. Kündig E. P., Garcia A. Diastereoselective and enantioselective reduction of tetralin-1,4dione. Beilstein. J. Org. Chem. 2008. V. 37, p. 37-41.

5. Garcia A., Ouizem S., Cheng X., Romanens P., Kündig E. P. Efficient Enantioselective syntheses of sertraline, 2-epicatalponol and catalponol from tetralin-1,4-dione. Adv. Synth. Catal. 2010. V. 352, p. 2306-2314.

6. Камший Л. П., Маматюк В. И., Коптюг В. А. Взаимодействие фенолов с кислотами Льюиса: 10. Комплексы диоксинафталинов с бромистым алюминием. ЖОрХ. 1974. Т. 10, c. 2194-2200. [Kamshiy L.P., Mamatuk V. I., Koptug V.A. Interaction of phenols with Lewis acids: 10. 
Complexes of dioxinaphthalenes with aluminum bromide. Rus. J. Org. Chem. 1974. Vol. 10, p. 21942200. (In Russ.)]

7. Межерецкий В. В., Тюрин Р. В., Миняева Л. Г., Антонов А. К., Задорожная А. П. Полиядерные гетероциклические системы на основе 1,3-нафталиндиола I. Взаимодействие 1,3-нафталиндиола и его производных с $\beta$-дикарбонилами и $\alpha, \beta$-непредельными дикарбонильными соединенями. ЖОрХ. 2006. Т. 42, с. 1473-1478. [Mezheritskii V. V., Tyurin R. V., Minyaeva L. G., Antonov A. N., Zadorozhnaya A. P. Polynuclear heterocyclic systems based on naphthakene-1,3-diol: I. Reaction of naphthalene-1,3-diol and its derivatives with $\beta$-dicarbonyl and $\alpha, \beta$-unsaturated carbonyl compounds. Rus. J. Org. Chem. 1974. Vol. 10, p. 2194-2200 (In Russ.)].

8. Mukhopadhyay P., Iwashita Y., Shirakawa M., Kawano S., Fujita N., Shinkai S. Spontaneous colorimetric sensing of the positional isomers of dihydroxynaphthalene in a $1 \mathrm{D}$ organogel matrix. Angew. Chem. Int. Ed. 2006. 45, p. 1592-1595.

9. El-Halawany A. M., Chung M. H., Nakamura N., Ma C.-M., Nishinara T., Hattori M. Estrogenic and anti-estrogenic activities of Cassia tora phenolic constituents. Chem. Pharm. Bull. 2007. V. 55, p. 1476-1482.

10. Russel G. A., Chen P., Kim B. H., Rajararnam R. Homolytic base-promoted aromatic alkylations by alkylmercury halides. J. Am. Chem. Soc. 1997. V. 119, p. 8795-8801.

11. Петерсон И.В., Соколенко В.А., Свирская Н.М., Рубайло А.И. С-алкилирование 1,4-дигидроксинафталина третичными спиртами. Журнал СФУ. Серия: Химия. 2010. Т. 3. C. 362-368. [Peterson I. V., Sokolenko W. A., Svirskaya N. M., Rubaylo A. I. C-alkylation of 1,4-dihydroxynaphthalene with tertiary alcohols. J. Siberian Fed. Univ. Chem. 2010. V. 3, p. 253-259 (In Russ.)].

12. Peterson I. V., Svirskaya N. M., Kondrasenko A. A., Rubaylo A. I. Preparation of adamantyl derivatives of 1,4-; 1,6- and 1,7-dihydroxynaphtalenes and assignment of their NMR data. Magn. Reson. Chem. 2013. V. 51, p. 762-766.

13. Петерсон И. В., Соколенко В. А., Свирская Н. М., Рубайло А. И. Синтез адамантильных производных 1,6- и 1,7-дигидроксинафталинов. Журнал СФУ. Серия: Химия. 2010. Т. 3. С. 362-368. [Peterson I. V., Sokolenko W. A., Svirskaya N. M., Rubaylo A. I. Synthesis of adamantyl derivatives of 1,6- and 1,7-dihydroxynaphthalenes. J. Siberian Fed. Univ. Chem. 2010. V. 3, p. 362-368 (In Russ.)].

14. Peterson I. V., Svirskaya N. M., Kondrasenko A. A., Rubaylo A. I.. Spectral assignment of new adamantane derivatives of 1,3-; 1,5-dihydroxy- and 1,5-dimethylnaphtalenes. Magn. Reson. Chem. 2015. V. 53, p. 323-326.

15. Петерсон И. В., Соколенко В. А., Свирская Н. М., Рубайло А. И. Алкилирование 1-адамантанолом 1,8- и 1,3-дигидроксинафталинов. Журнал СФУ. Серия: Химия. 2016. Т. 9, С. 134139. [Peterson I. V., Sokolenko W. A., Svirskaya N. M., Rubaylo A. I. 1-Adamantanol alkylation of 1,8- and 1,3- dihydroxynaphthalenes. J. Siberian Fed. Univ. Chem. 2016. V. 9, p. 134-139 (In Russ.)]. 